\title{
Role of Adenosine in Regulating Fetal Sleep States and Breathing Activity
}

\author{
A review of: Koos BJ, Maeda T, and Jan C 2001 Adenosine $A_{1}$ and $A_{2 A}$ receptors modulate sleep state and breathing \\ in fetal sheep. J Appl Physiol 91:343-350; and Koos BJ, Maeda T 2001 Adenosine $\mathrm{A}_{2 \mathrm{~A}}$ receptors mediate \\ cardiovascular responses to hypoxia in fetal sheep. Am J Physiol Heart Circ Physiol 280:H83-H89
}

$\mathrm{T}_{2}$ HE SEARCH FOR understanding the mechanisms underlying the regulation of fetal sleep states and respiratory activity has been the subject of much investigation over the last 30 years since the original observations of Dawes et al. (1). Fetuses make fetal breathing movements (FBM) approximately $30 \%$ of the time during late gestation and these are generally associated with low-voltage electrocortical activity (LVECoG). An understanding of the factors that regulate FBM under both normal and hypoxic conditions is of particular importance since the presence or absence of FBM is commonly used in clinical practice to assess fetal health.

The neuromodulator, adenosine, has been studied extensively with regards to its role in regulating both fetal sleep states and FBM under physiologic and pathophysiologic conditions. The actions of adenosine may be mediated through one or more of its known receptor subtypes: $\mathrm{A}_{1}, \mathrm{~A}_{2 \mathrm{~A}}$, $A_{2 B}$, or $A_{3}$. Both adenosine and it's $A_{1}$ receptor agonists when administered either centrally (2) or peripherally (3) to the ovine fetus lead to a decrease in incidence of LVECoG, eye movements, and FBM. Koos et al. (4) have now confirmed that adenosine influences fetal sleep states and FBM through its actions on both $\mathrm{A}_{1}$ and $A_{2 A}$ receptor subtypes. Of note, $A_{1}$ activation does not appear to have a tonic effect on fetal behavioral state, whereas $\mathrm{A}_{2 \mathrm{~A}}$ receptors exert a tonic inhibitory effect on REM sleep. It is of note that adenosine receptor subtypes are present throughout the brain and therefore adenosine may exert differential effects on fetal respiratory control depending on the receptor subtype and location of action. For example, the data from Koos et al. (4) suggests that the medullary $A_{1}$ receptors are important for breath amplitude but not rhythm or incidence of FBM. In addition, there is a regional variation in levels of extracellular adenosine in the ovine fetal brain with levels being substantially higher in the cortex compared to the brainstem.

\section{Alan Bocking}

Adenosine is also important in mediating the effects of hypoxia on fetal sleep states, breathing and cardiovascular control. Both maternally induced fetal hypoxia and hypoxia secondary to umbilical cord occlusions in fetal sheep lead to increases in cerebral extracellular adenosine levels $(5,6)$. Like adenosine, acute hypoxia leads to an inhibition of FBM, which is an important energy-saving adaptation by the fetus in the situation of overall reduced oxygen delivery. This effect occurs above the level of the medulla since discrete neuronal lesions of the posteromedial thalamus abolish both the hypoxia and adenosine-induced inhibition of FBM. In addition to its effect on FBM, adenosine causes a decrease in overall fetal oxygen consumption as well as decreases in oxygen consumption in specific organ beds such as the brain and heart. The role of adenosine and its receptor subtypes in mediating the adaptation of FBM to prolonged hypoxia when there is a return of FBM to normal incidence over a period of hours remains unknown.

In a separate paper, Koos et al. (7) have provided further evidence that the effects of acute hypoxia on cardiovascular reflexes are mediated through the action of adenosine on its $\mathrm{A}_{2 \mathrm{~A}}$ receptor subtypes. This action most likely takes place within the carotid body since the reflex bradycardia, hypertension, and systemic vasoconstriction, which occur with acute hypoxia, are abolished by prior carotid body denervation (8). In addition, with prolonged infusions, $\mathrm{A}_{2 \mathrm{~A}}$ agonists give rise to a tachycardia, which is thought to be centrally mediated. An interesting finding of Koos et al. (7) is that although the infusion of specific $\mathrm{ADO} \mathrm{A}_{1}$ receptor blockers to fetal sheep does not alter fetal heart rate or blood pressure directly, there is a significant tachycardia and hypertension present when the infusion is stopped which is as yet unexplained.
Adenosine is also important in mediating the inhibition of FBM, which occurs with maternal ethanol administration in pregnant sheep. Fetal cerebral cortical extracellular fluid levels of adenosine increase with ethanol and are associated with a decrease in the incidence of FBM as well as LVECoG (9). This inhibitory effect of ethanol on FBM is also blocked by the A1 receptor antagonist 8-CPT (10) in keeping with the primary action of adenosine on respiratory control being mediated through the $A_{1}$ receptor subtype.

1. Dawes GS, Fox HE, Leduc BM, Liggins GC, Richards RT 1972 Respiratory movements and rapid eye movement sleep in the foetal lamb. J Physiol 220:119-143

2. Bissonette JM, Hohimer AR, Knopps SJ 1991 The effect of centrally administered adenosine on fetal breathing movements. Respir Physiol 84:273-285

3. Koos BJ, Matsuda K 1990 Fetal breathing, sleep state and cardiovascular response to adenosine in sheep. J Appl Physiol 68:489-495

4. Koos BJ, Maeda T, Jan C 2001 Adenosine $A_{1}$ and $\mathrm{A}_{2 \mathrm{~A}}$ receptors modulate sleep state and breathing in fetal sheep. J Appl Physiol 91:343-350

5. Koos BJ, Mason BA, Punla O, and Adinolfi AM 1994 Hypoxic inhibition of breathing in fetal sheep: relationship to brain adenosine concentration. J Appl Physiol 77:2734-2739

6. Watson CS, Schaefer R, White SE, Homan JH, Fraher L, Harding R, Bocking AD 2002 Effect of intermittent umbilical cord occlusion on fetal respiratory activity and brain adenosine in late-gestation sheep. Reprod Fertil Dev 14:1-9

7. Koos BJ, Maeda $T 2001$ Adenosine $A_{2 A}$ receptors mediate cardiovascular responses to hypoxia in fetal sheep. Am J Physiol Heart Circ Physiol 280:H83-H89

8. Giussani DA, Spencer JAD, Moore PJ, Bennet L, Hanson MA 1993 Afferent and efferent components of the cardiovascular responses to acute hypoxia in term fetal sheep. J Physiol 461:431-449

9. Watson CS, White SE, Homan JH, Kimura KA, Brien JF, Fraher L, Challis JR, Bocking AD 1999 Increased cerebral extracellular adenosine and decreased $\mathrm{PGE}_{2}$ during ethanol-induced inhibition of FBM. J Appl Physiol 86(4):1410-1420

10. Watson CS, White SE, Homan JH, Fraher L, Brien JF, Bocking AD 1999 The adenosine A(1)-receptor antagonist 8-CPT reverses ethanol-induced inhibition of fetal breathing movements. J Appl Physiol 87(4):1333-1338

Department of Obstetrics and Gynaecology

University of Western Ontario

Lawson Health Research Institute

268 Grosvenor Street

London, Ontario N6A $4 \mathrm{~V} 2$

Canada 